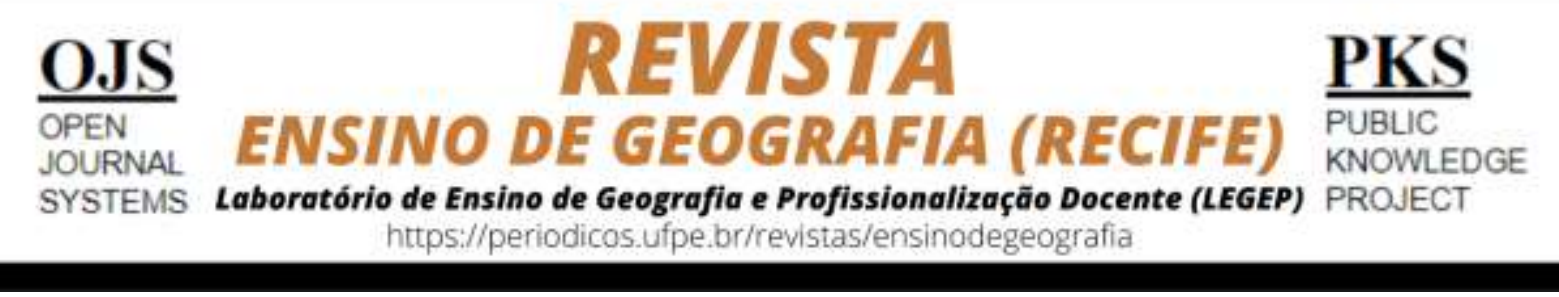

\title{
CONSUMO CONSCIENTE POR MEIO DA EDUCAÇÃO AMBIENTAL NA ESCOLA
}

\author{
Leandra de Lourdes Rezende Amaral ${ }^{1}$, Gabriel Gonçalves Arantes ${ }^{2}$, Maria Beatriz \\ Junqueira Bernardes ${ }^{3}$
}

\begin{abstract}
${ }^{1}$ Doutoranda no Programa de Pós-Graduação de Geografia do Instituto de Geografia da Universidade Federal de Uberlândia. E-mail: leandra.amaral2008@gmail.com - ORCID iD: http://orcid.org/0000-0002-1104-037X

${ }^{2}$ Mestrando no Programa de Pós-Graduação de Geografia do Instituto de Geografia da Universidade Federal de Uberlândia. E-mail: gabriel_goncalvesarantes@hotmail.com - ORCID iD: http://orcid.org/0000-0002-72067146

${ }^{3}$ Professora Doutora do Instituto de Geografia da Universidade Federal de Uberlândia. E-mail: mbeatriz@ufu.br - ORCID iD: http://orcid.org/0000-0001-7002-2182
\end{abstract}

Artigo recebido em 12/03/2020 e aceito em 06/04/2020

\begin{abstract}
RESUMO
Este trabalho se debruçou em pesquisar um referencial teórico capaz de embasar a produção de propostas e ações para a efetivação da Educação Ambiental (EA) na escola por meio da transversalidade. Segue com apoio da CAPES (Coordenação de Aperfeiçoamento de Pessoal de Nível Superior) instigando debates acerca da relação entre EA e a construção do consumo consciente no ambiente escolar. A pesquisa aponta uma abordagem qualitativa com enfoque na Educação Ambiental Crítica. Para tal, é necessário que reconheçamos a importância de avançar na apropriação de instrumentos que contribuam para a produção da criticidade na reflexão das ações a valores sociais materializados na escola. Assim, apresentamos o projeto "Consumo consciente, escola inteligente", para ser implantado na Educação Básica, ensino fundamental II. Por meio deste é possível relacionar a EA e os conteúdos de diversos saberes, utilizando assuntos que envolvem o cotidiano escolar e ações nesse espaço, culminando para além do olhar crítico, mas, o olhar capaz de propor soluções que equilibrem o consumo e o meio em que se encontram.
\end{abstract}

Palavras-chave: Cotidiano Escolar; Transversalidade; Criticidade.

\section{CONSCIOUS CONSUMPTION THROUGH ENVIRONMENTAL EDUCATION IN SCHOOL}

\section{ABSTRACT}

This paper focused on researching a theoretical framework capable of supporting the production of proposals and actions for the realization of Environmental Education (AE) at school through transversality. It continues with support from CAPES (Coordenação de Aperfeiçoamento de Pessoal de Nível Superior/Higher Education Personnel Improvement Coordination) instigating debates about the relationship between EE and the construction of conscious consumption in the school environment. The research points to a qualitative approach focusing on Critical Environmental Education. For this, we need to recognize the importance of advancing in the appropriation of instruments that contribute to the production of criticality in the reflection of actions to social values materialized in school. Thus, we present the project "Conscious Consumption, Smart School", to be implemented in Basic Education, elementary school II. Through it, it is possible to relate the EE and the contents of various knowledge, using subjects that involve the daily school and actions in this space, culminating beyond the critical view, but the view able to propose solutions that balance consumption and the environment.

Keywords: School Life; Transversality; Criticality. 


\section{INTRODUÇÃO}

A pesquisa tem como objetivo refletir sobre a Educação Ambiental (EA) na Educação Básica em busca de instigar debates sobre a importância de sua abordagem permeada na transversalidade dos currículos, para que se consiga estabelecer relações entre o sujeito com o meio ambiente. E assim, possibilitar a construção de uma tomada de consciência ambiental em prol de estimular mudanças de atitudes frente ao cotidiano escolar e extra-escola.

Para tal, será necessário partirmos de um referencial teórico capaz de oferecer embasamento para discutirmos conceitos relevantes para a pesquisa, tais como: Educação Ambiental (EA); tomada de consciência ambiental; e consumo consciente.

Desse modo, o artigo justifica-se pela necessidade de transformar a prática educativa no intuito de, com a EA, promover a qualidade de ensino e da vida dos sujeitos pertencentes à comunidade escolar dentro e fora do espaço da instituição de ensino. Assim, evidenciamos que a EA na Educação Básica poderá, por meio da transversalidade, permitir o enfrentamento da problemática ambiental contemporânea do espaço próximo, vivido e experimentado do educando.

A metodologia empregada tem por base referencial teórico e a construção de uma proposta de intervenção para ser aplicada na escola nos anos finais do Ensino Fundamental, para de forma prática construir juntos, (educadores e educandos) uma consciência ambiental iniciada a partir do consumo consciente.

\section{Transversalidade x Interdisciplinaridade - Educação Ambiental x Educação Básica}

Junto com a contemporaneidade surgem os avanços tecnológicos que nos levam a utopia do desenvolvimento, este que nos direciona aos questionamentos: Pra quem? A que custo? Sabemos que os avanços são necessários, mas devemos em conjunto com eles pensar em uma melhor maneira de desenvolvermos, não apenas economicamente, mas evoluirmos como cidadãos conscientes de que somos parte integrante desse ambiente.

Assim, os educadores devem construir em conjunto com os educandos um olhar holístico sobre seu espaço cotidiano e como suas atitudes podem contribuir positiva ou negativamente sobre o ambiente. Sendo assim, a partir da compreensão do que vem a ser Educação Ambiental e como esta pode contribuir para a tomada de consciência ambiental por meio da Educação Básica, partiremos do pressuposto da transversalidade das disciplinas, pois como apresenta Sato (2001, p. 24) “a dimensão ambiental pode ser transversalizada nas diversas 
áreas do conhecimento, respeitando as organizações, os objetos e as necessidades das múltiplas relações" e acrescenta que, "vale ressaltar que transversalidade e interdisciplinaridade são paradigmas situados nas esteiras de uma lógica interna, de construção democrática e muitas vezes, de morosidade complexa" (SATO, 2001, p. 24).

Para avançarmos na reflexão, necessitamos compreender o que vem a ser transversalidade e interdisciplinaridade, logo o Conselho Nacional de Educação (CNE) discorre sobre a transversalidade e a interdisciplinaridade no Parecer $\mathrm{N}^{\circ} 7$, de 7 de abril de 2010:

\begin{abstract}
A transversalidade orienta para a necessidade de se instituir, na prática educativa, uma analogia entre aprender conhecimentos teoricamente sistematizados (aprender sobre a realidade) e as questões da vida real (aprender na realidade e da realidade). Dentro de uma compreensão interdisciplinar do conhecimento, a transversalidade tem significado, sendo uma proposta didática que possibilita o tratamento dos conhecimentos escolares de forma integrada. Assim, nessa abordagem, a gestão do conhecimento parte do pressuposto de que os sujeitos são agentes da arte de problematizar e interrogar, e buscam procedimentos interdisciplinares capazes de acender a chama do diálogo entre diferentes sujeitos, ciências, saberes e temas (CNE/CEB, 2010, p. 24).
\end{abstract}

Diante do pressuposto do CNE compreendemos que a transversalidade e a interdisciplinaridade são diferentes, porém, complementares, enquanto a transversalidade apresenta a dimensão didático-pedagógica, a interdisciplinaridade refere-se à forma de como o conhecimento será produzido.

Assim sendo, segundo Brasil (2019, p. 7) os Temas Contemporâneos Transversais (TCTs) são aqueles que não pertencem a uma área específica do conhecimento, mas que atravessam por elas, trabalhando com a realidade do educando, ou seja, aqueles que induzem e são induzidos pelo processo educacional. Em prol de ampliar a concepção de Temas Transversais a BNCC (Base Nacional Comum Curricular) incorpora o termo Contemporâneo, pois deseja evidenciar o caráter de atualidade desses temas e sua relevância na Educação Básica. Desse modo, houve, também, a ampliação dos temas, que os PCNs (Parâmetros Curriculares Nacionais) apresentavam em seis temáticas, a BNCC aponta seis macroáreas temáticas envolvendo 15 Temas contemporâneos, que podem ser conferidos no esquema abaixo (figura $1)$. 


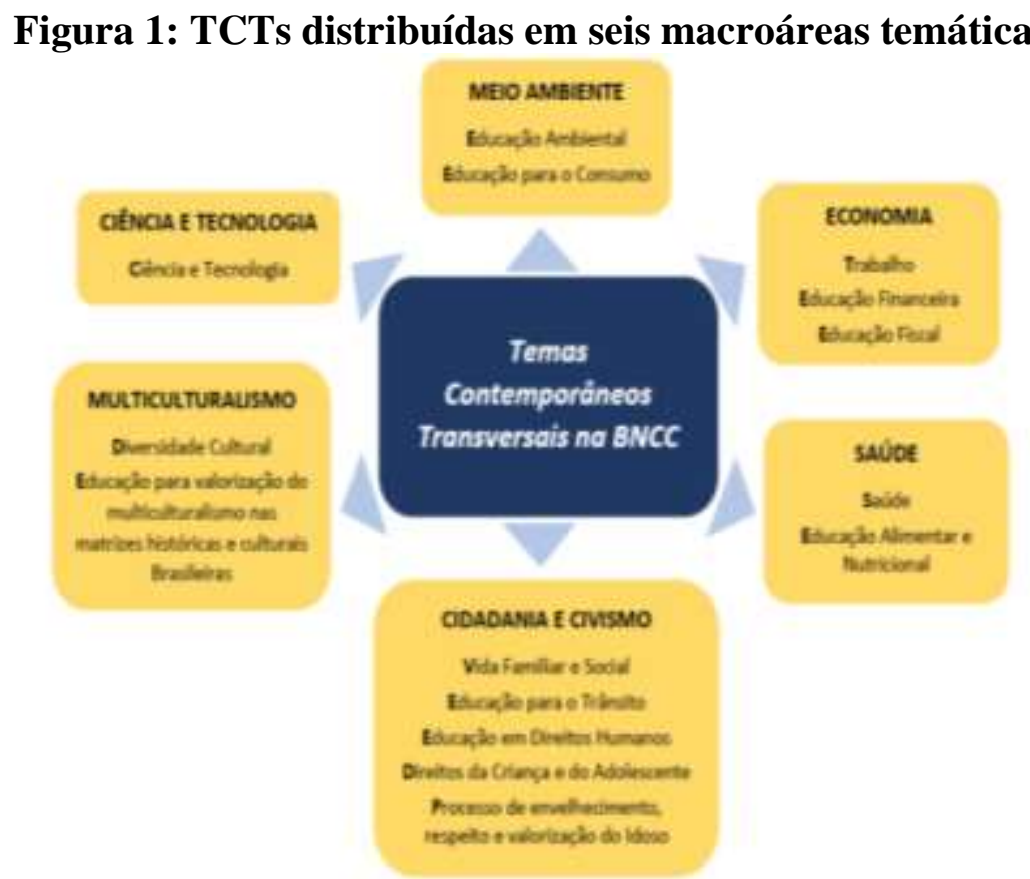

Fonte: Temas Contemporâneos Transversais na BNCC: contexto histórico e pressupostos pedagógicos, 2019.

Portanto, para compreender a transversalidade de EA é necessário rompermos com os padrões da sociedade contemporânea que, cada vez mais, se volta ao individualismo, só assim, caminharemos rumo à coletividade. Pois, como argumenta Guimarães (2004) à compreensão de mundo da atualidade apresenta dificuldades em pensar o conjunto, ou seja, "pela prevalência da parte na compreensão e na ação sobre o mundo, desponta características da vida moderna que são individuais e sociais: sectarismo, individualismo, competição exacerbada, desigualdade e espoliação, solidão e violência" (GUIMARÃES, 2004, p. 26).

Para tanto, apresentamos a pesquisa numa visão voltada para a Educação Ambiental Crítica, que segundo Guimarães (2004, p.28)

\begin{abstract}
Dentro desta concepção, a Educação Ambiental Crítica se propõe em primeiro lugar. A desvelar esses embates presentes, para que numa compreensão (complexa) do real se instrumentalize os atores sociais para intervir nessa realidade. Mas apenas o desvelamento não resulta numa ação diferenciada, é necessária a práxis, em que a reflexão subsidie numa prática criativa e essa prática dê elementos para uma reflexão e construção de uma nova compreensão de mundo. Mas esse não é um processo individual, mas que o indivíduo vivencia na relação com o coletivo em um exercício de cidadania, na participação em movimentos coletivos conjuntos de transformação da realidade socioambiental.
\end{abstract}

O que o autor nos apresenta é a necessidade de trabalharmos com uma EA que seja capaz de fazer com que o educando participe da sua realidade, permitindo ampliar o pensamento à reflexão e a crítica. E assim, se envolver com propostas de ações capazes de resolver os problemas comunitários. Desse modo, é possível imprimir nos sujeitos envolvidos no processo 
da EA, valores e ações à transformação humana e social e para preservação ecológica como aponta Guimarães (1995).

Nesse sentido, apontamos os argumentos de Carvalho (2004, p. 18) “o projeto políticopedagógico de uma Educação Ambiental Crítica seria o de contribuir para uma mudança de valores e atitudes, contribuindo para a formação de um sujeito ecológico." Ou seja, é importante pensarmos em uma educação pautada por "sensibilidades solidárias com o meio social e ambiental" (CARVALHO, 2004, p. 19)

Ainda sobre a EA crítica Carvalho (2004) nos faz refletir que a responsabilidade pelo planeta parte de uma responsabilidade consigo mesmo, com os outros e com o ambiente, sem dividir ou priorizar por níveis de poder as grandezas da ação do ser humano. Pois, segundo Guimarães (1995, p. 33) “o avanço científico e tecnológico desse período histórico permitiu um grande aumento da população humana sobre o planeta, refletindo a dominação dessa espécie sobre as demais; população que assume como sociedade uma postura destrutiva na relação ser humano/natureza e na relação ser humano/ser humano".

Assim, para que a EA consiga alcançar a plenitude é necessário que o educando seja sensibilizado frente a sua realidade local, de modo a trabalhar com sua experiência cotidiana almejando uma vivência integral. Desse modo, esse pressuposto nutri o sujeito a possibilidade da construção da tomada de consciência ambiental.

\section{Como se constrói uma consciência ambiental?!}

A preocupação com o futuro do meio ambiente começa a aparecer na sociedade de forma mais abundante a partir da década de 1970. A maneira com que a população consumia e desperdiçava os recursos em uma progressão geométrica começou a despertar dúvidas sobre a viabilidade de se manter o consumo desenfreado. Assim, para auxiliar na construção de uma consciência ambiental surge a necessidade de se trabalhar a Educação Ambiental em ambientes formais e não formais de ensino.

Desse modo, optamos por trabalhar com a EA em ambientes formais de ensino, para tal, consideramos alguns conceitos necessários a serem trabalhados no processo de produção da tomada de consciência ambiental autônoma e crítica por parte de educadores e educandos, frente à realidade dos mesmos. As preocupações com o meio ambiente fazem surgir então conceitos e pensamentos novos, como sustentabilidade e a educação ambiental, que aparece como uma ferramenta essencial na implantação da consciência crítica ambiental: 
Com o passar do tempo surgiram conceitos voltados à manutenção e conservação do meio ambiente e suas espécies naturais. Estes estudos voltam a atenção pela busca de compreensão das fontes causadoras de desequilíbrio nessas interações, procurando identificar os pontos onde o espaço habitado foi desviado, causando tal desequilíbrio. A educação ambiental nos incita a desenvolver nosso conhecimento, habilidades e atitudes voltadas à ecologia, à preservação do meio ambiente e das espécies que nele habitam. Também está relacionada com áreas de pesquisa e análise, e principalmente conscientização das pessoas quanto às responsabilidades sobre o meio ambiente, visando prepara-las para a preservação e uso sustentável dos recursos disponíveis na natureza. (PENSAMENTO VERDE, 2013).

Diante do exposto pelo site Pensamento Verde (2013) a EA nos instiga a pensar como partes integrantes desse meio ambiente e não separado dele, assim, assumindo nossa responsabilidade frente à preservação e uso sustentável dos recursos naturais disponíveis na natureza. Desse modo, torna-se necessário apresentarmos o conceito de sustentabilidade, definido de maneira bem sucinta por Vargas $(2015$, p. 2)

[...] utilizar os recursos que a natureza oferece, da maneira mais eficiente e eficaz possível, de forma econômica, buscando o menor impacto ao equilíbrio entre o meio ambiente e o modo de vida humano.

Pensando nesse viés, a sustentabilidade é essencial para que o equilíbrio, entre o consumo da população e a maneira como o meio ambiente dispõe dos recursos, seja alcançado. O consumo da população deve ser pensado e realizado de forma responsável, de modo a não exaurir os recursos disponíveis na Terra. Assim, segundo Boff (2010, p. 111)

\footnotetext{
Sustentável seria aquele crescimento econômico e desenvolvimento social que se fizessem de acordo com a comunidade de vida, que produzissem conforme a capacidade do bioma, que atendessem com equidade as demandas de nossa geração sem, sacrificar o capital natural, e que estivessem abertos às demandas das gerações futuras.
}

Ou seja, o autor nos leva a refletir a importância de equilibrar o consumo com o meio ambiente, sem que este seja sacrificado a médio e longo prazo. É inegável que o consumo faz parte da história da sociedade humana, sendo à base da sua manutenção e crescimento, marcando presença de maneiras variadas no decorrer da trajetória humana. Analisando essa trajetória, passamos por um consumo de sobrevivência, colhendo, caçando e pescando aquilo que era essencial para manter a vida e com o decorrer da linha cronológica da história e as subsequentes transformações no cenário mundial, como o avanço da tecnologia, ordenação dos mercados, revolução industrial, o consumo se modificou até se tornar um ponto mandatório de crescimento econômico, baseado em necessidades utópicas e até exageradas reforçadas por um 
trabalho midiático em nome do acúmulo econômico desenfreado que o capitalismo busca. $\mathrm{O}$ consumismo trouxe muitos problemas, como dito por Vargas $(2015$, p.3):

O modo de vida da sociedade, os métodos de consumo dos recursos (energia, água, matérias primas) e, principalmente, o modo de eliminar os rejeitos dos produtos consumidos no ambiente, resultaram em graves consequências ao planeta. Entre elas, pode-se exemplificar com: desertificações, mudanças climáticas, alteração nas correntes marítimas, queda na produtividade dos solos, desgelo polar, buracos na camada de ozônio, entre outros, que gravemente afetam o ecossistema terrestre.

No século XX, com uma nova reordenação de valores impulsionada pelas preocupações ambientais que tomaram força a partir da década de 70 e 80 , o modo de consumo passa por uma etapa de transformação, com o consumidor buscando alterar seus valores e modo de consumo, refletindo mais sobre o impacto deste no futuro. Surge então o ideal do consumo consciente.

Com base no Instituto Akatu (2017) - ONG que busca mobilização da sociedade para o Consumo Consciente -, seis perguntas bastam para orientar o desenvolvimento do consumo consciente: "Por que comprar? O que comprar? Como comprar? De quem comprar? Como usar? Como descartar?"

Portanto, compreendemos que o consumo consciente é uma forma de consumo que busca o menor impacto ambiental possível, procurando benefícios para a sociedade e a população, quebrando os moldes de consumo exagerado e que almeja manter o desenvolvimento econômico global relacionado à estabilidade ambiental e justiça social. Podemos perceber que os conceitos de sustentabilidade e consumo consciente estão interligados de forma íntima, sendo um essencial para a prática do outro.

Retomando o conceito de Educação Ambiental, segundo Dias (1992) esse é apresentado como sendo teorias e práticas ambientais, capazes de orientar a resolução de problemas reais, permeados pela interdisciplinaridade com envolvimento individual e coletivo, ativo e responsável. Assim, a EA tem um diálogo com a transversalidade do ensino por incorporar as dimensões sociais, políticas, econômicas, culturais, ecológicas e éticas das mais variadas disciplinas, não ficando presa a somente uma em específico, sendo passível de contribuição de todas elas.

Durante o Fórum Global da Conferência Rio-92, a educação ambiental foi uma das pautas e teve princípios formulados para ações em prol de sociedades sustentáveis e responsabilidade global, sendo alguns desses princípios:

A educação ambiental é um direito de todos; somos todos aprendizes e educadores. A educação ambiental deve ter como base o pensamento crítico e inovador, em qualquer 
tempo ou lugar em seus modos formal, não-formal e informal, promovendo a transformação e a construção da sociedade. A educação ambiental é individual e coletiva. Tem o propósito de formar cidadãos com consciência local e planetária, que respeitem a autodeterminação dos povos e a soberania das nações. A educação ambiental não é neutra, mas ideológica. É um ato político. A educação ambiental deve envolver uma perspectiva holística, enfocando a relação entre o ser humano, a natureza e o universo de forma interdisciplinar. A educação ambiental deve estimular a solidariedade, a igualdade e o respeito aos direitos humanos, valendo-se de estratégias democráticas e da interação entre as culturas. A educação ambiental deve tratar as questões globais críticas, suas causas e inter-relações em uma perspectiva sistêmica, em seu contexto social e histórico. Aspectos primordiais relacionados ao desenvolvimento e ao meio ambiente, tais como população, saúde, paz, direitos humanos, democracia, fome, degradação da flora e fauna, devem se abordados dessa maneira. (RIO 92, 1992, p. 1-2)

Frente à importância da EA no ambiente formal de ensino, nos debruçamos a construir uma proposta de intervenção no ambiente escolar voltado à produção de uma tomada de consciência crítica sobre o consumo na escola, tornando-a palpável por meio de ações dos educandos e educadores para com o meio em que vivem cotidianamente.

\section{Praticando o consumo consciente}

Diante do explanado anteriormente, foi possível compreender alguns conceitos básicos para se trabalhar com EA e, principalmente, para se construir uma tomada de consciência ambiental. Neste tópico nos atentaremos a apresentar uma proposta de ação, a ser desenvolvida nos anos finais do ensino fundamental, no intuito de promover a construção do consumo consciente nos sujeitos envolvidos no processo de EA.

Pois, como afirma Guimarães (1995, p. 74)

A ciência e a tecnologia melhoraram extraordinariamente a vida do homem; elevando os padrões de vida, facilitando o trabalho, combatendo doenças e criando novos produtos. Todavia essas conquistas resultam em crescentes pressões sobre o nosso planeta. Nem todos se beneficiam igualmente desse progresso.

Com essa afirmativa do autor, podemos compreender a necessidade de consumirmos de forma consciente, pois, ao contrário o resultado pode ser catastrófico, visto que o planeta não suportará a pressão resultante do crescimento econômico. Visto que, por detrás dos benefícios tecnológicos, podemos nos deparar, com o descaso e a degradação ambiental. Para Guimarães (1995, p. 75): “O progresso econômico dos países depende das riquezas naturais. Quando a atividade econômica destrói nossa base de recursos, o desenvolvimento é prejudicado", no entanto, é preciso ter consciência que a qualidade de vida encontra-se inseparável a manutenção do equilíbrio ecológico do meio ambiente local e global. 
Assim, como resultado da EA espera-se que o educando consiga elaborar "uma visão síntese (consciência planetária) com novos valores e atitudes em sua relação com o ambiente, exercendo uma cidadania planetária comprometida com a qualidade de vida do ambiente como um todo" (GUIMARÃES, 1995, p. 48).

Portanto, para auxiliar nessa empreitada de alcançar a consciência planetária apresentamos atividades para serem desenvolvidas entre educadores e educandos em prol da produção de um novo conhecimento ampliado da realidade vivenciada, pautando-se na construção do consumo consciente por todos.

Mas, antes de iniciarmos a falar das atividades em si, precisamos ter em mente que é possível alcançarmos a consciência ambiental por meio de atitudes simples no nosso cotidiano. Assim, pensando no ambiente escolar elencamos algumas dessas possibilidades para já iniciarmos nas ações individuais e com características pequenas, mas que se somadas coletivamente, com certeza farão a diferença. Afinal, para todo começo é necessário o primeiro passo.

Que tal começarmos por refletir sobre o consumismo?! O que consumimos? Como consumimos? Que destino é dado aos resíduos que foram produzidos? Tudo que compramos são necessários ou essenciais para a vida? Como podemos equilibrar nosso consumo com os resíduos que produzimos? E na escola como isso pode ser feito?

$\mathrm{Na}$ escola várias ações podem ser realizadas para minimizar o consumo, tais como: utilizar o verso do papel para rascunho; fazer impressão frente e verso sempre que possível; atividades para anos mais avançados na alfabetização produzir utilizando fonte menor para aproveitar melhor a folha; não deixar torneira aberta; desligar lâmpadas e equipamentos eletroeletrônico ao sair do ambiente; não desperdiçar a comida do lanche; reutilizar materiais escolares (cadernos com folhas em branco, mochilas, lápis etc) no próximo ano. São atitudes, aparentemente, simples que farão muita diferença ao final de um ano.

A EA por possuir característica transversal, não necessita ser específica de um determinado ano ou disciplina ela pode ser trabalhada em conjunto com o conteúdo de qualquer disciplina, ou seja, independente do componente curricular. Porém, como adverte Guimarães (1995, p. 31)

No trabalho de conscientização é preciso estar claro que conscientizar não é simplesmente transmitir valores 'verdes' do educador para o educando; essa é a lógica da educação 'tradicional'; é, na verdade, possibilitar ao educando questionar criticamente os valores do próprio educador que está trabalhando em sua conscientização. É permitir que o educando construa o conhecimento e critique valores a partir de sua realidade, [...]. 
Partilhando do pensamento de Guimarães (1995) trabalharemos com propostas que vai de encontro à construção da criticidade frente à realidade vivida e ao incentivo a mudança de atitudes diárias, individuais e coletivas, na escola na intencionalidade de extrapolar esse ambiente. A partir daqui apresentaremos um projeto para ser desenvolvido nas escolas de Educação Básica nos anos finais do ensino fundamental e intitulamos o mesmo de: "Consumo consciente, Escola inteligente".

\section{Consumo consciente, Escola inteligente}

Esse projeto visa à necessidade de construir na comunidade escolar uma tomada de consciência voltada ao consumo e a realização de ações para que não haja desperdício e subutilização do recurso, em vista de redução de gastos pela instituição e diminuição de resíduos no meio ambiente.

Desse modo, serão realizadas atividades através de projeções de vídeos educativos que envolvem a temática, tal como Liga Sustentável (2018); pesquisa pelos alunos sobre o consumo e desperdício na escola (papel pela secretaria; alimentos na cantina; água; energia elétrica etc); produção de cartazes incentivando a comunidade escolar ao consumo consciente.

Para melhor organização o projeto está divido em três etapas, estas que não se encontram isoladas e sim inter-relacionadas com o processo de ensino aprendizagem das disciplinas e conteúdos programáticos da educação básica. Foram utilizadas as mesmas etapas apresentadas por Guimarães (1995), quando o mesmo tratou de planejamento participativo, porém adaptamos a temática e a realidade.

I Etapa: Levantamento e diagnóstico

Neste primeiro momento os alunos são direcionados a (re)conhecerem o ambiente escolar e as relações de consumo existentes no seu espaço. Segundo Guimarães (1995, p. 45) “[...] como ponto de partida serão buscados os diferentes saberes, as experiências, as expectativas e os problemas existentes, criando um vínculo do processo com a realidade do educando em sua prática social para vir a ser transformada." Nessa ocasião nos pautaremos ao que é consumido pela escola, papel, alimentos, água, energia elétrica etc., com a finalidade de diagnosticar os excessos que poderão ser minimizados com a adoção do consumo consciente.

II Etapa: Plano de ação

O plano de ação é a etapa de criar metodologias que permitam, como apresenta Guimarães (1995, p. 46), “aos envolvidos no processo uma vivência intensa através da 
construção de novos conhecimentos, valores e atitudes que darão conta da multiplicidade e da abrangência dos aspectos que constituem a realidade trabalhada, local/global”.

III Etapa: Execução

No desempenho do plano de ação, o educando é capaz de construir conhecimentos que gerem novos valores e atitudes na relação ser humano/consumo consciente no ambiente escolar e extra-escolar.

Ao final do ano letivo será realizada a exposição dos resultados do trabalho de pesquisa e ação, no intuito de perceber se houve mudanças, significativas, nas atitudes de consumo dos sujeitos envolvidos no processo. Para a culminância os educandos, embora orientados pelo educador, serão autônomos na escolha da forma com que irão apresentar para a comunidade escolar seus resultados, por exemplo, por meio de cartazes contendo gráficos indicando o consumo de cada mês com papel para impressão. A partir dessa informação avaliar se houve alteração no consumo após a intervenção dos educandos com ações para a conscientização ambiental. Dentre outras possibilidades que serão apresentadas pelos próprios educandos.

\section{Considerações finais}

Diante das pesquisas realizadas e a produção de ações de intervenção no ambiente escolar por meio do Projeto "Consumo consciente, Escola inteligente" compreendemos que a escola é um espaço propício para explorar tal temática em busca da construção de uma consciência crítica e dialética de mundo por meio do consumo consciente, das atitudes individuais e coletivas iniciadas na comunidade escolar.

Mudar nosso modo de ver e agir sobre o ambiente que está próximo de nós é possível, desde que instrumentalizados com práticas alternativas adequadas de intervenção sobre o meio, diagnosticados os problemas e incentivados a buscar soluções compreendendo que somos parte integrante desse ambiente e o que o afeta, também, mais cedo ou mais tarde nos afetará.

Assim, construir uma tomada de consciência crítica participativa nos remete a trabalhar com valores e ações capazes de transformar o ser humano e a sociedade rumo à preservação ecológica e a formação da cidadania assimilando a visão holística entre humanidade e natureza. Porém, é necessário lembrarmos que o trabalho de conscientização só será alcançado quando o educando conseguir pensar de forma questionadora e crítica as ações e valores estabelecidos pela sociedade. 
Portanto, concluímos que a Educação Ambiental na educação básica, por meio da transversalidade, corrobora com a ampliação das discussões sobre os problemas gerados pelo ser humano no ambiente escolar frente ao consumo e ressalta a postura dos sujeitos quanto à resolução dos mesmos com adaptação de cada realidade. Nesse momento devemos frisar que, a EA não apresenta uma neutralidade frente aos problemas sociais, porém proporciona um pensamento ideológico que deve ser seguido. Desse modo, compreendemos a EA como temática que extrapola as questões curriculares e os limites físicos da própria comunidade escolar.

\section{REFERÊNCIAS}

BOFF, L.. Cuidar da Terra, proteger a Vida: como evitar o Fim do Mundo. Rio de Janeiro: Record, 2010.

BRASIL. Secretaria de Educação Fundamental. Parâmetros Curriculares Nacionais: apresentação dos Temas Contemporâneos Transversais, ética/Secretaria de Educação Fundamental. Brasília: MEC/SEF, 1997.

Ministério da Educação. Temas Contemporâneos Transversais na BNCC: contexto histórico e pressupostos pedagógicos. MEC, 2019. Brasília, DF, 2019. Disponível em <http://basenacionalcomum.mec.gov.br/images/implementacao/contextualizacao_temas_cont emporaneos.pdf> Acesso em 01 Nov. 2019.

CARVALHO, I. C. de M. Educação ambiental crítica: nomes e endereçamentos da educação. In: Identidades da educação ambiental brasileira / Ministério do Meio Ambiente. Diretoria de Educação Ambiental; Philippe Pomier Layrargues (coord.). - Brasília: Ministério do Meio Ambiente, 2004, p. 13-24.

CNE/CEB (Conselho Nacional de Educação/Câmara de Educação Básica). Resolução No 7, de 07 de abril de 2010. Fixa Diretrizes Curriculares Nacionais Gerais para a Educação Básica. Diário Oficial da União, Brasília, 09 de julho de 2010, Seção 1, p. 24. Disponível em: < http://portal.mec.gov.br/index.php?option=com_docman\&view=download\&alias=5367pceb007-10\&category_slug=maio-2010-pdf\&Itemid=30192>. Acesso em: 01 Nov. 2019.

DIAS, G. F. Educação ambiental: princípios e práticas. São Paulo, Gaia, 1992. 
INSTITUTO AKATU. Conheça as 6 perguntas do consumo consciente que ajudam a diminuir impactos negativos no meio ambiente. Akatu. 30 de maio de 2017. Disponível em: < https://www.akatu.org.br/releases/conheca-as-6-perguntas-do-consumo-consciente-queajudam-diminuir-impactos-negativos-no-meio-ambiente/> Acesso em: 10 de Out. 2019.

GUIMARÃES, M. Educação ambiental crítica. In: Identidades da educação ambiental brasileira / Ministério do Meio Ambiente. Diretoria de Educação Ambiental; Philippe Pomier Layrargues (coord.). - Brasília: Ministério do Meio Ambiente, 2004, p. 25-34.

A dimensão ambiental na educação. Campinas, SP: Papirus, 1995, 107 p.

LIGA sustentável. Produção FCDL/Santa Catarina. Santa Catarina, 2018. 4 vídeo 4'34”. Disponível em < http://ligasustentavel.com.br/videos/4o-episodio/> Acesso em: 07 de out. 2019.

REDAÇÃO PENSAMENTO VERDE. Ecologia e educação ambiental por um futuro melhor. Pensamento Verde, 23 de Mai., 2013. Disponível em: $<$ https://www.pensamentoverde.com.br/atitude/ecologia-e-educacao-ambiental-por-umfuturo-melhor/\#>. Acesso em: 10 de out. 2019.

RIO 92. Tratado de educação ambiental para sociedades sustentáveis e responsabilidade global. Documento elaborado pelo Fórum Global das Organizações Não Governamentais, na Conferência das Nações Unidas sobre o Meio Ambiente e Desenvolvimento. Rio de Janeiro, 1992.

Disponível em <http://portal.mec.gov.br/secad/arquivos/pdf/educacaoambiental/tratado.pdf> Acesso em: 10 de Out. 2019.

SATO, M. Apaixonadamente pesquisadora em educação ambiental. Educação: Teoria e Prática. Vol. 9, nº 16, jan-jul, 2001 e nº 17, jul-dez, 2001, p. 24-35.

VARGAS, C. B. de. Sustentabilidade e Consumo Consciente: A Percepção da Evolução do Modo de Consumir e como isso Pode Afetar a Gestão nos Próximos Anos. In: XV Mostra de Iniciação Científica, Pós-Graduação, Pesquisa e Extensão, 1, 2015, Caxias do Sul, 2015. p. 02-06. 